\title{
Anti-Inflammatory Mechanisms of Novel Synthetic Ruthenium Compounds
}

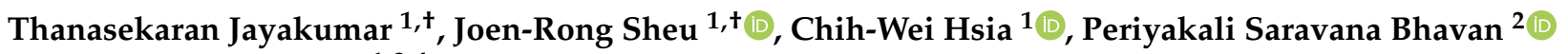 \\ and Chao-Chien Chang 1,3,4,* \\ 1 Graduate Institute of Medical Sciences, College of Medicine, Taipei Medical University, Taipei 110, Taiwan; \\ jayakumar@tmu.edu.tw (T.J.); sheuj@@tmu.edu.tw (J.-R.S.); d119106003@tmu.edu.tw (C.-W.H.) \\ 2 Department of Zoology, Bharathiar University, Coimbatore 641046, India; bhavan@buc.edu.in \\ 3 Department of Cardiovascular Center, Cathay General Hospital, Taipei 106, Taiwan \\ 4 School of Medicine, College of Medicine, Fu Jen Catholic University, New Taipei City 242, Taiwan \\ * Correspondence: cgh05761@cgh.org.tw \\ + These authors contributed equally to this work.
}

Citation: Jayakumar, T.; Sheu, J.-R.;

Hsia, C.-W.; Bhavan, P.S.; Chang,

C.-C. Anti-Inflammatory Mechanisms of Novel Synthetic Ruthenium Compounds. Appl. Sci. 2021, 11, 10092. https://doi.org/10.3390/ app112110092

Academic Editor: Bruno Chrcanovic

Received: 25 September 2021

Accepted: 23 October 2021

Published: 28 October 2021

Publisher's Note: MDPI stays neutral with regard to jurisdictional claims in published maps and institutional affiliations.

Copyright: (c) 2021 by the authors. Licensee MDPI, Basel, Switzerland. This article is an open access article distributed under the terms and conditions of the Creative Commons Attribution (CC BY) license (https:/ / creativecommons.org/licenses/by/ $4.0 /)$.

\begin{abstract}
Inflammation is the primary biological reaction to induce severe infection or injury in the immune system. Control of different inflammatory cytokines, such as nitric oxide (NO), interleukins (IL), tumor necrosis factor alpha-(TNF- $\alpha$ ), noncytokine mediator, prostaglandin E2 (PGE2), mitogen activated protein kinases (MAPKs) and nuclear factor kappa B (NF- $\mathrm{kB}$ ), facilitates antiinflammatory effect of different substances. Coordination metal complexes have been applied as metallo-drugs. Several metal complexes have found to possess potent biological activities, especially anticancer, cardioprotective, chondroprotective and anti-parasitosis activities. Among the metallo drugs, ruthenium-based $(\mathrm{Ru})$ complexes have paid much attention in clinical applications. Despite the kinetic nature of $\mathrm{Ru}$ complexes is similar to platinum in terms of cell division events, their toxic effect is lower than that of cisplatin. This paper reviews the anti-inflammatory effect of novel synthetic Ru complexes with potential molecular mechanisms that are actively involved.
\end{abstract}

Keywords: ruthenium compounds; anti-inflammatory effects; MAPKs; NF-кB; inflammatory cytokines; ROS

\section{Introduction}

Microorganisms such as bacteria, viruses or fungi induce inflammation when they typically enter the body, exist in specific tissues and/or flow in the blood [1,2]. Various processes such as tissue injury, cell death, cancer, ischemia and degeneration may also induce inflammation [3-5]. Different types inflammatory responses secret inflammatory mediators, which are normally separated into two main categories such as pro- and antiinflammatory mediators. Inflammatory mediators that have been widely investigated in response with human pathological conditions are cytokines, chemokines and strong inflammatory transcription factor nuclear factor $\mathrm{\kappa} B(\mathrm{NF}-\mathrm{kB})$.

Tumor necrosis factor (TNF)- $\alpha$ is a vital pro-inflammatory cytokine secreted from various cells and shows several cellular effects $[6,7]$. This cytokine has been connected with several disease states in humans, including cancer and psychiatric disorders. Interleukins (IL-1 $\alpha$ ) is another important cytokine, which mostly exerts a pro-inflammatory activity $[8,9]$. IL-1 $\alpha$ has also been acted as anti-inflammatory cytokine. Similarly, IL-6 acts as a pro-inflammatory cytokine but it has some anti-inflammatory effects. In contrast, IL-10 is a potent anti-inflammatory cytokine which obstructs the action of many proinflammatory mediators $[10,11]$. The transcription factor NF- $\mathrm{KB}$ is a noticeable controller of immune and inflammatory responses, as it is extremely associated in the pathophysiology of cancer [12,13]. In a resting (un-stimulated) condition NF- $\mathrm{kB}$ exists in the cytoplasm, 
however upon activation by various inflammatory stimuli, this transcription factor translocates into the nucleus and stimulate transcription of several genes that are associated with inflammatory events [13].

Nuclear factor erythroid 2-related factor2 (Nrf2) signaling molecule is reported to inhibit inflammation-mediated neuronal toxicity via its anti-inflammatory mechanism. Studies have found the increased neuroinflammatory M1 markers cyclooxygenase (COX-2) and induced nitric oxide synthase (iNOS) and decreased M2 markers (IL-4, IL-10, and Arg1) in neurotoxins induced Nrf2-deficient mice [14,15]. Moreover, other investigation was proposed that Nrf2 may be a regulator of the M2 phenotype [15]. Association of Nrf2 in microglia immunomodulation, mainly, oxidative stress-induced neuroinflammation was found to protect by heme oxygenase-1 (HO-1), a crucial enzyme for cellular protection [16] For instance, activation of HO-1 inhibits lipopolysaccharide (LPS)-induced inflammation in mouse peritoneal macrophages and microglia [17]. Microglial activation has been noted in the penumbra after middle cerebral artery occlusion (MCAO) injury [18]. Recently, researchers have been paid attention to recover post stroke induced inflammation by controlling microglia function using various drugs and/or natural products [19]. Therefore, controlling of proinflammatory mediators and NF- $\mathrm{kB} / \mathrm{Nrf} 2 / \mathrm{HO}-1$ by any substances may reduce neuroinflammation and its related diseases.

\section{Metal Complexes in Anti-Inflammatory Therapy}

Recently, organometallic complexes have been used in chemotherapeutic studies because of their chemical structure diversity and easy control of the hydrophobic nature of the arene or the cyclopentadienyl moiety [20-22]. The arene and cyclopentadienyl rings of metal complexes demonstrated potent effects because of their good cellular uptake and for the functional mode toward biological targets [23]. Cisplatin has been considered as the best alternate for the treatment of various tumors; however, it has limitations because of its cellular toxicity and drug-resistance [24]. Copper-aspirin complex has found to be effective in vivo anti-inflammatory effects than the well-established anticancer drug aspirin [25]. Zinc complex has been reported to condense carrageenan induced inflammatory edema in the paws of rats [26]. Anti-inflammatory properties of copper (II), cobalt (II) and manganese (II) complexes have also been well studied [27]. Despite various types of metal complexes having been established for the treatment of inflammatory diseases, they still have some limitations, including dose-limiting side effects and resistance after several use in treatment. Therefore, development of suitable metal complexes for anticancer treatment has received much attention.

\section{Anti-Inflammatory Ruthenium Metal Complexes}

Application of organometallic ruthenium complexes have been increased for the different types of cancer treatment, and also regularly applied as potential alternatives for existing therapeutic strategies. This metal complex is also a prominent alternative to platinum as it is suitable for balanced anticancer drug design [28]. Thus, ruthenium metal complexes are measured as the most inspiring anticancer agents. So far, NAMI-A and KP1019 ruthenium complexes have entered clinical trials. NAMI-A is an active drug against lung cancer [29]. Studies on the anticancer activity of ruthenium (II) complexes have significantly increased, as numerous $\mathrm{Ru}(\mathrm{II})$ complexes display encouraging anticancer effects [30,31]. The increasing use of $\mathrm{Ru}(\mathrm{II})$ complexes on cancer cells provides more insight into their bioactivity, to support several medical claims. We identified the antiplatelet and antithrombotic effects of several new ruthenium complexes [32-34]. Novel ruthenium complexes, such as [Ru(pyridin-2-yl)-quinoline) $\left(\eta^{6}-p\right.$-cymene) $\mathrm{Cl}^{6} \mathrm{BF}_{4}$ (TQ-1), $\left[\mathrm{Ru}\left(2-\left(\right.\right.\right.$ pyridin-2-yl)-quinoxaline) $\left(\eta^{6}-p\right.$-cymene) $\mathrm{Cl}^{-} \mathrm{BF}_{4}$ (TQ-2), [Ru(diphenyl-2(pyridin-2yl)-quinolin-6-yl)-amine)( $\eta^{6}-p$-cymene)Cl]BF 4 (TQ-4) and [Ru(2-(1H-benzoimidazol-2-yl)quinoline) $\left(\eta^{6}-p\right.$-cymene $) \mathrm{Cl}^{6} \mathrm{BF}_{4}$ (TQ-6) have been prepared according to the method described by Li et al. [35] for their anti-inflammatory evaluation. Synthetic methods of the ligands and complexes are shown in Figure 1A,B. 
A

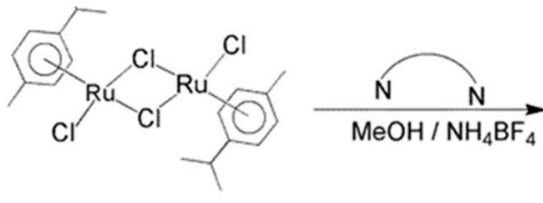

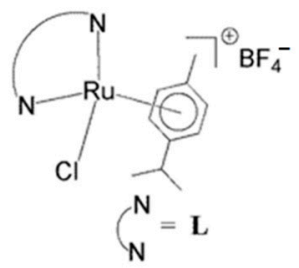

B

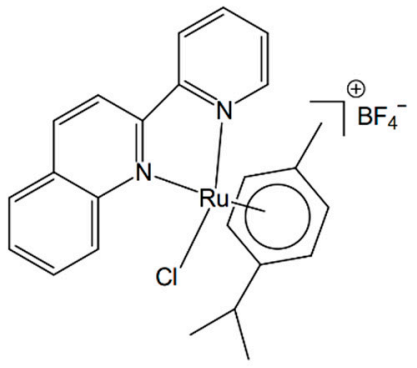

TQ-1

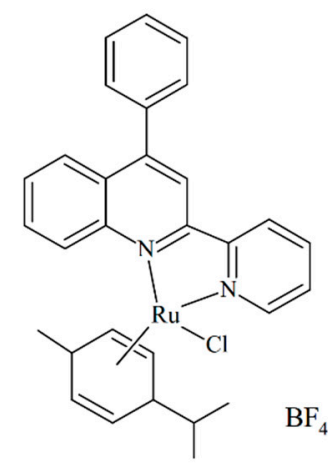

TQ-4

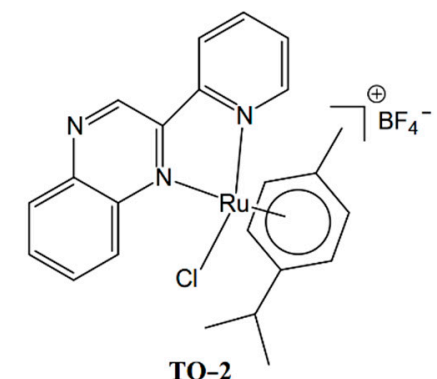

TQ-2

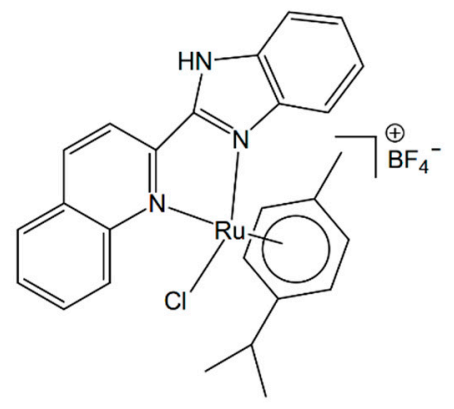

TQ-6

Figure 1. Scheme of synthesis of ligands (A) and complexes (B) of ruthenium compounds.

\section{Ruthenium Compounds Recover Inflammatory Mediators}

Alanine transaminase (ALT) and aspartate transaminase (AST) are the major liver marker enzymes increased in serum could specify the loss of hepatocyte structural integrity and liver injury [36]. One study has found that among the TZP $(1,2,4)$ triazole[4,3-a]pyridine derivatives, derivative $8 \mathrm{~d}$ expressively reserved concanavalin A-induced ALT and AST activities in mice liver [37]. L6H21, a derivative of chalcone, had been found to reduce ethanol and LPS induced inflammation by reducing ALT and AST [38]. Consistent with these findings, our group have discovered that among the tested ruthenium (TQ) compounds, TQ 4 strikingly reduces the serum levels of ALT and AST in the LPS-injected mice, whereas TQ-1 and 2 did not alter these enzymes [39].

Lipopolysaccharide induce inflammatory events via increasing proinflammatory cytokines TNF- $\alpha$, IL- 6 and IL- $1 \beta$, thus reduction of these cytokines could decrease inflammatory responses. The increased expression of iNOS induces inflammation and liver injury via the production of $\mathrm{NO}$, an additional activator involves in oxidative stress mediated inflammation [40]. Furthermore, in the LPS induced inflammation, a considerable amount of $\mathrm{NO}$ is found to increase by the elevated synthesis of iNOS. In this regard, it can be considered as NO activation might be an initial marker in inducing liver damage, and hence inhibition of $\mathrm{NO}$ could be a target for controlling inflammation. NO are produced by macrophages. Microglia respond strongly to an LPS exposure and induce NO along with several inflammatory cytokines. NO is regarded as a toxic mediator in microglia-mediated brain inflammation [41]. Also, LPS induce macrophage activation through NO production. Our studies have found TQ compounds TQ-4 inhibits NO and iNOS [39], and TQ-6 inhibits 
NO, iNOS and COX-2 in LPS induced macrophages and microglia [42], respectively, as shown in Figures 2 and 3.

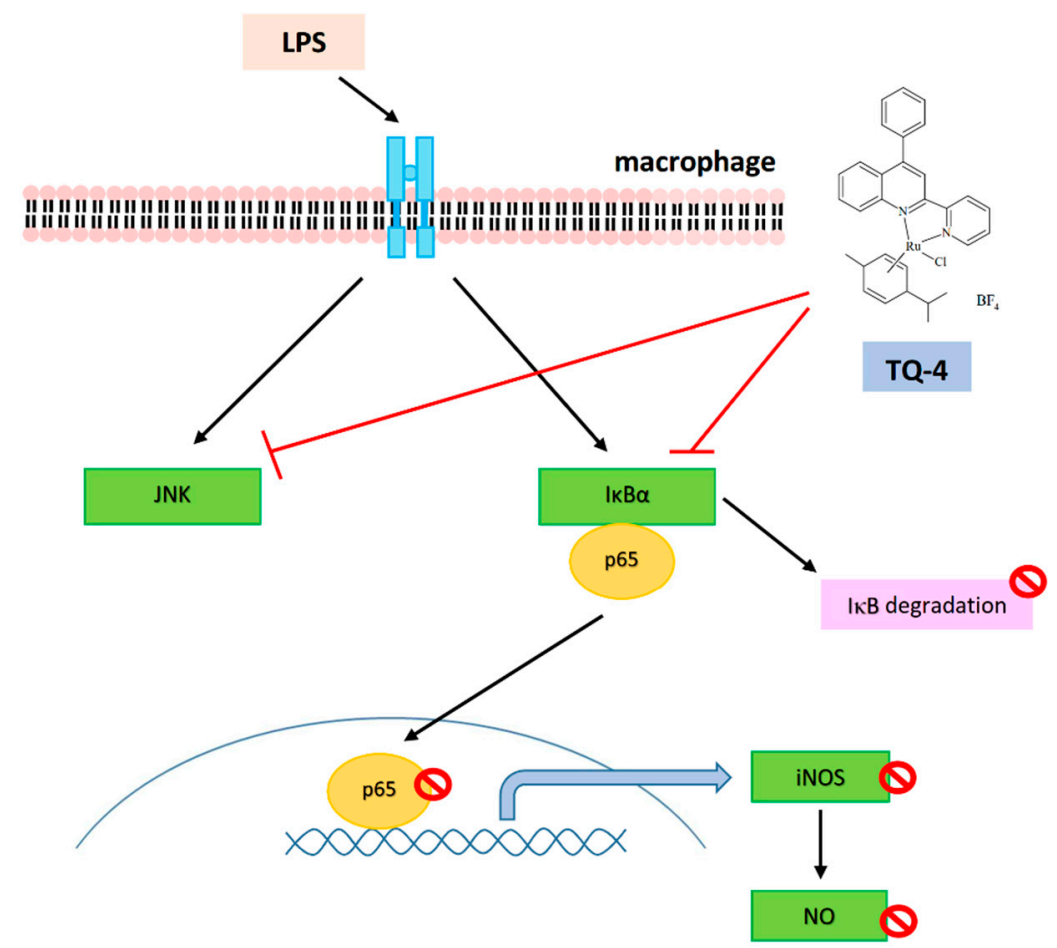

Figure 2. In vitro anti-inflammatory mechanism of TQ-4 compound: TQ-4 inhibits NO production and iNOS expression, JNK phosphorylation, I $\mathrm{B} \mathrm{B} \alpha$ degradation, NF- $\mathrm{kBp} 65$ phosphorylation and its nuclear translocation in LPS-induced RAW 264.7 cells.

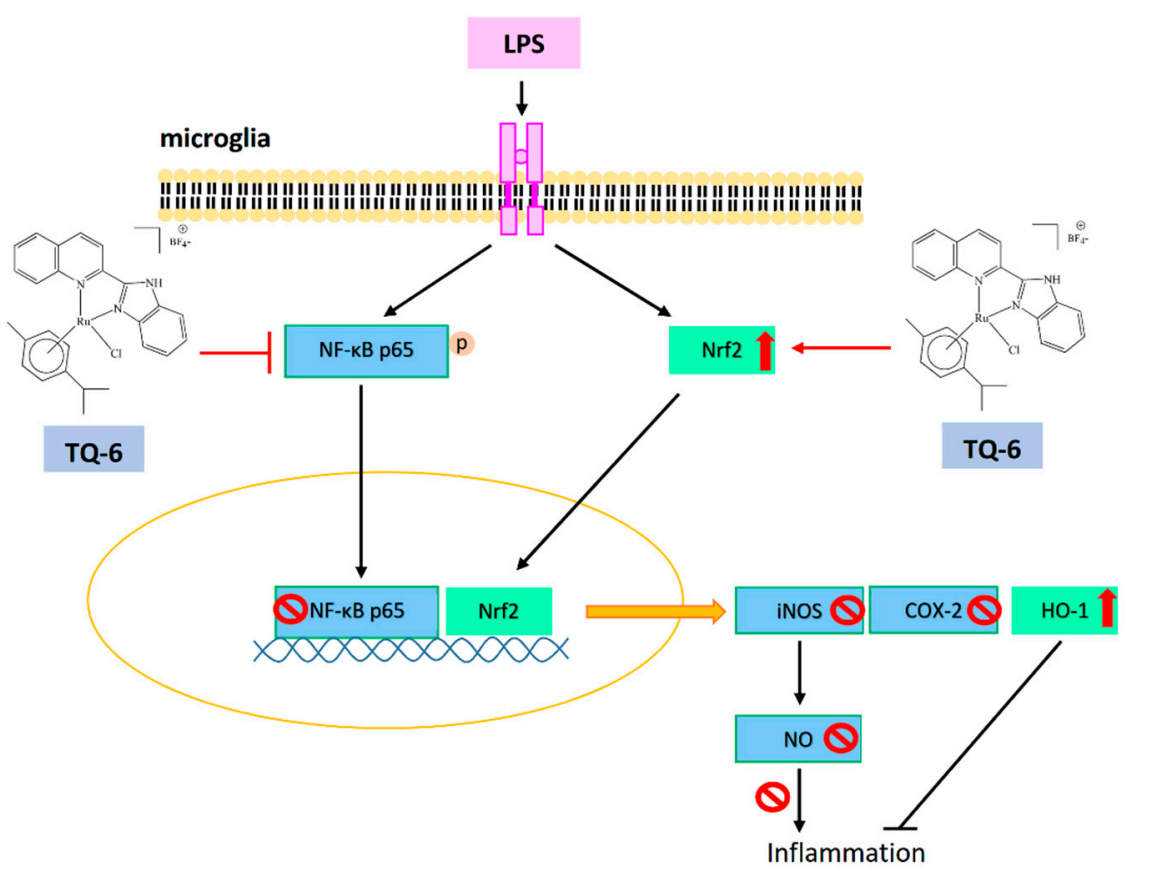

Figure 3. TQ-6 effectively reduced inflammatory mediators NO, iNOS, COX-2 and NF-kB p65 phosphorylation and its nuclear translocation in LPS-stimulated microglia. TQ-6 increased the expression of nuclear factor erythroid 2-related factor 2 (Nrf2) and hemeoxygenase-1(HO-1). 


\section{Anti-Inflammatory Mechanisms of Ruthenium Compounds}

Several types of signaling molecules play critical role in the progress of cellular structures and function [43]. Therefore, it is imperative to understand how ruthenium complexes interact with definite targets within cells to investigate the anti-inflammatory mechanism.

\subsection{Involvement of MAPKs in Anti-Inflammatory Ruthenium Complexes}

Proteins that are associated with mitogen-activated protein kinases (MAPKs) and NF- $k B$ pathway have been scrutinized to distinguish the mechanisms of TQ compounds on their protective effects against inflammatory events. Studies have projected that over activation of MAPKs, including ERK, p38 and JNK involve in controlling inflammatory cytokines and mediators in activated macrophages, and hence, suppression of MAPK activation is reported to reduce the expression of inflammatory mediators and improves inflammatory disease [44]. Our previous study found increased phosphorylation of p38MAPK, ERK and JNK in LPS induced macrophages [39]. Jayakumar et al. have found that among the compounds tested (TQ-1, 2 and 4) only TQ-4 inhibits the phosphorylation of JNK, but not p38 and ERK in the LPS-induced mice liver and RAW cells (Figure 4) [39]. Similarly, a study has detected the anti-inflammatory effects of selenium coated nanoparticles via inhibition JNK1/2, but not ERK1/2 phosphorylation of [45]. From these results, it can be proposed that JNK contributes critical role for the anti-inflammatory effects of ruthenium TQ-4.

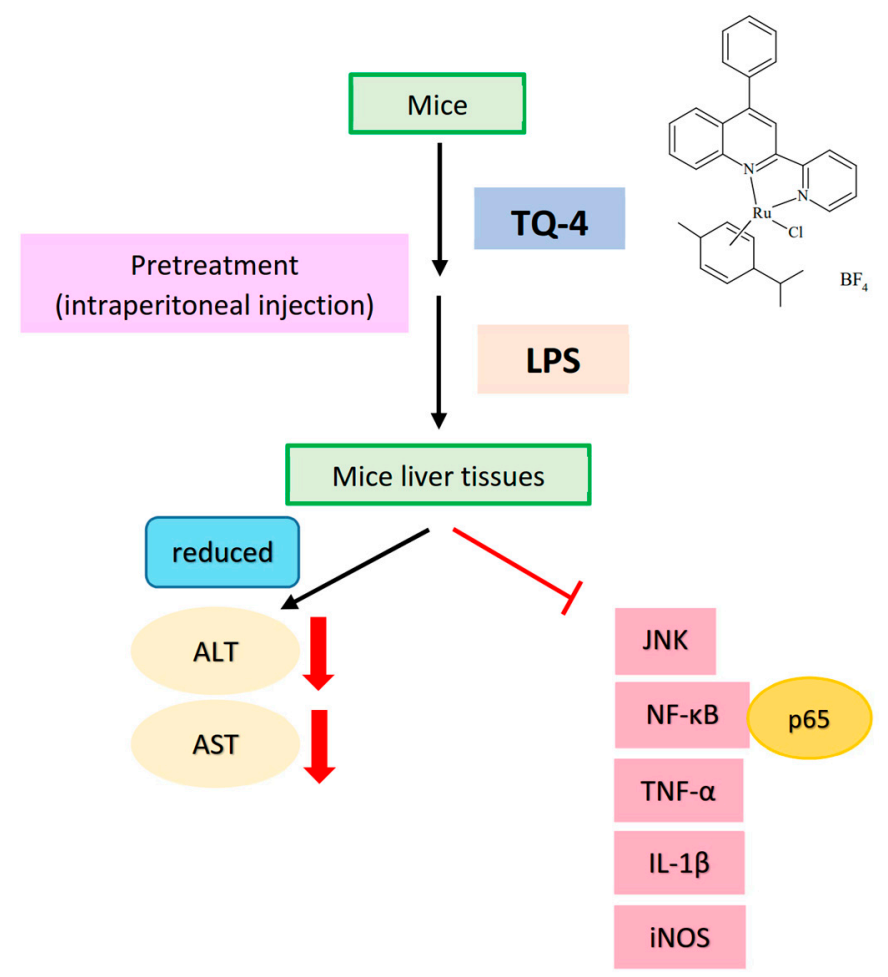

Figure 4. In vivo anti-inflammatory mechanism of TQ-4: TQ-4 effectively reduced LPS-induced serum alanine transaminase (ALT), aspartate transaminase (AST), TNF- $\alpha$, IL-1 $\beta$, iNOS, NF-kB p65 and JNK phosphorylation in LPS-induced mice liver tissues.

\subsection{Targeting NF- $\kappa B$ and Nrf2 in Anti-Inflammatory Ruthenium Compounds}

Nuclear factor kappa B (NF- $\mathrm{kB}$ ) transcription factor is an upstream regulator of inflammatory mediator $\mathrm{NO}$, and a major target for treating inflammatory diseases [46]. Evidence has proved that NF- $\mathrm{KB}$ activation in microglia stimulates the expression of proinflammatory cytokines and activators [47]. Inhibition of NF- $\mathrm{kB}$ signaling in microglia was proposed as the major target of drugs to exhibit the protective effect against the neuropathology of ischemic stroke [48]. As shown in Figures 2 and 3, LPS induces NF-kB 
activation and its nuclear translocation and ІкB $\alpha$ degradation in LPS treated macrophages was found to be recovered by TQ-4 [39] and TQ-6 [42].

Nuclear factor erythroid 2-related factor 2 (Nrf2), a key transcription factor, plays a vibrant role in controlling oxidative stress-mediated inflammatory responses. Normally, Nrf2 is stored in the cytoplasm with its inhibitor Keap1. In an activated state, like NF$\mathrm{KB}$, this transcription factor translocates into the nucleus and regulates the transcription of antioxidant enzyme HO-1 [49]. An investigation stated that Nrf2 deficient mice are more vulnerable to LPS-induced neuroinflammation [50]. Additionally, Nrf2 activation in microglia attenuates neuroinflammation via inhibiting NF- $\mathrm{kB}$-associated inflammatory mediators [14]. For instance, thymoquinone, a major component of Nigella sativa inhibits neuroinflammation by activating Nrf2 and inhibiting NF- $\mathrm{kB}$ [51]. Thus, we also explored the anti-inflammatory effects of TQ-6 through NF- $\mathrm{kB}$ and Nrf2 signaling; the results determined that TQ-6 inhibited NF- $\mathrm{KB}$ expression and its nuclear translocation, and also increased the expression of Nrf2 and HO-1 [42]. Nrf2 protects brain cells from ischemic stroke injury, as evidenced by increasing cerebral infarction ratio and neurological deficits score in Nrf2 knockout ischemic reperfusion induced rats [52]. The novel ruthenium compound TQ-6 potently reduced brain infarct volume and edema in middle cerebral artery occlusion (MCAO) induced mice (Figure 5) [42]. Consequently, the protective effect of TQ-6 in microglia by regulating Nrf2/HO-1 could be regarded as an ideal therapeutic target for the treatment of stroke associated inflammatory events.

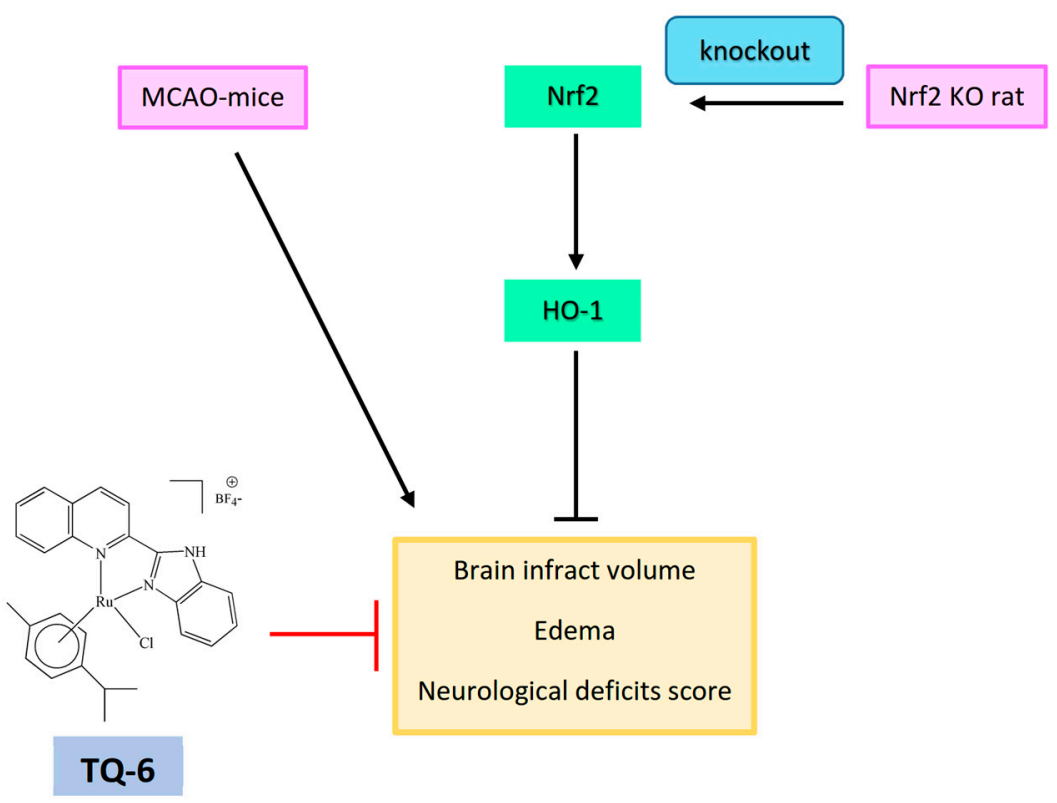

Figure 5. TQ-6 reduced infarct volume and edema in middle cerebral artery occlusion (MCAO)induced mice brain tissues. Nrf2 protects brain cells from ischemic stroke injury by decreasing cerebral infarction ratio and neurological deficits score in ischemic reperfusion induced rats.

\subsection{Target of Free Radicals for Anti-Inflammatory Ruthenium Compounds}

Reactive oxygen species (ROS) are generated by a host of exogenous routes. Environmental substances including non-genotoxic carcinogens directly produce or indirectly stimulate ROS in cells. ROS-mediated oxidative stress has been reported to stimulate in response to several xenobiotic compounds. LPS induces generation of ROS and NO along with several proinflammatory cytokines [53]. Several studies have proposed that NF- $\mathrm{kB}$ and ROS are the major targets for treating inflammatory diseases via inhibiting proinflammatory mediators and liver injury. In the event of ischemia-induced neuronal injury, ROS contribute destructive role by damaging lipids, proteins and nucleic acids, resulting to brain damage and cellular death [54]. An earlier finding discovered hydroxyl radicals $(\mathrm{OH} \bullet)$ dramatically increased in LPS-stimulated microglia [42]. LPS stimulates liver injury 
via increased ROS production and thus antioxidants are regarded as the greatest choice to repair this injury [55]. In this regard, our study had found that Ru compound TQ-6 and TQ-4 potently condensed the raised level of LPS-induced OH•; TQ-4 also potently scavenged (Fenton reaction, Figure 6), signifying that the defending effects of TQ-6 and TQ-4 in microglia and macrophage activation and ischemic stroke may partly be associated with $\mathrm{OH} \bullet$ inhibition.

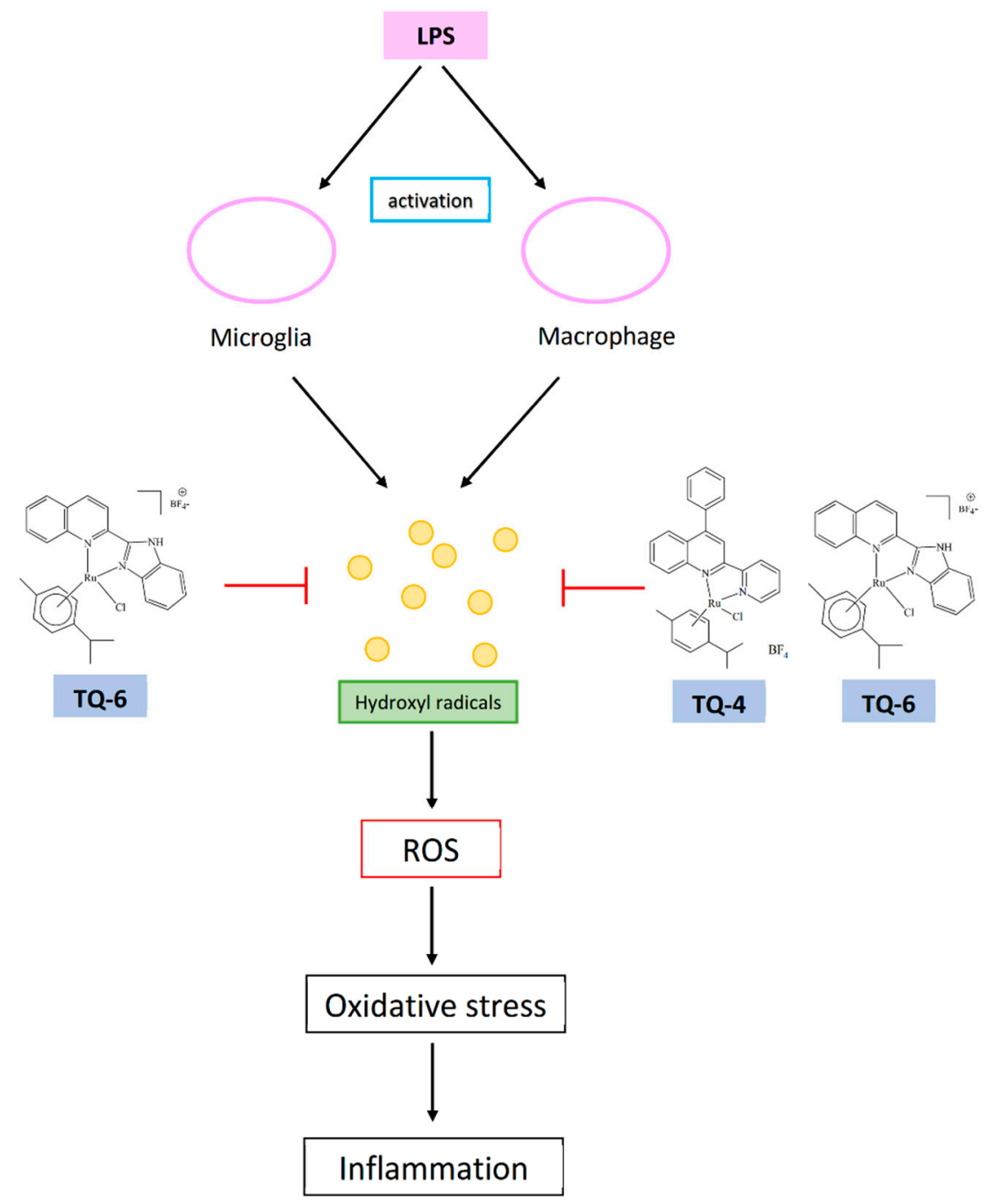

Figure 6. Ruthenium compounds TQ-4 and TQ-6 show anti-inflammatory effects via inhibiting OH• radical in LPS induced microglia/macrophages.

\section{Conclusions}

Progressive research work in inorganic medicinal chemistry has created new vision in the field of synthesis of novel metal complexes with high therapeutic values. As platinum and ruthenium complexes have recognized their contribution as antineoplastic agents and gold complexes are being applied in the treatment of arthritis, innovative metal complexes with better efficiency and less side effects are being developed with new practices. This review shortly summarizes anti-inflammatory activity and the underlying mechanisms of action of few novel ruthenium complexes. Ruthenium compounds show attractive anti-inflammatory activity both in vitro and in vivo animal models. Future research on ruthenium complexes as anti-inflammatory agents will confidently prove positive in advancing inorganic metal complexes as chemical spaces. 
Author Contributions: T.J. and J.-R.S. designed and wrote the paper. C.-W.H. and P.S.B. helped to draw diagrams. C.-C.C. collected literature, and was involved in editing the manuscript. All authors have read and agreed to the published version of the manuscript.

Funding: Ministry of Science and Technology of Taiwan (MOST 107-2320-B-038-035-MY2 and MOST108-2320-B-038-031-MY3), Taipei Medical University (DP2-107-21121-N-02), and Cathay General Hospital (CGH-MR-A11005).

Institutional Review Board Statement: Not applicable.

Informed Consent Statement: Not applicable.

Data Availability Statement: All data generated in this study are available in this published article.

Conflicts of Interest: The authors declare no conflict of interests.

\section{References}

1. Artis, D.; Spits, H. The biology of innate lymphoid cells. Nature 2015, 517, 293-301. [CrossRef]

2. Pedraza-Alva, G.; Pérez-Martínez, L.; Valdez-Hernández, L.; Meza-Sosa, K.F.; Ando-Kuri, M. Negative regulation of the inflammasome: Keeping inflammation under control. Immunol. Rev. 2015, 265, 231-257. [CrossRef]

3. Rock, K.L.; Lai, J.J.; Kono, H. Innate and adaptive immune responses to cell death. Immunol. Rev. 2011, 243, 191-205. [CrossRef]

4. Heppner, F.L.; Ransohoff, R.M.; Becher, B. Immune attack: The role of inflammation in Alzheimer disease. Nat. Rev. Neurosci. 2015, 16, 358-372. [CrossRef]

5. Waisman, A.; Liblau, R.S.; Becher, B. Innate and adaptive immune responses in the CNS. Lancet Neurol. 2015, 14, 945-955. [CrossRef]

6. Montgomery, S.L.; Bowers, W.J. Tumor necrosis factor-alpha and the roles it plays in homeostatic and degenerative processes within the central nervous system. J. Neuroimmune Pharmacol. 2012, 7, 42-59. [CrossRef] [PubMed]

7. Zelová, H.; Hošek, J. TNF- $\alpha$ signalling and inflammation: Interactions between old acquaintances. Inflamm. Res. 2013, 62, 641-651. [CrossRef] [PubMed]

8. Fenton, M.J. Review: Transcriptional and post-transcriptional regulation of interleukin 1 gene expression. Int. J. Immunopharmacol. 1992, 14, 401-411. [CrossRef]

9. Rider, P.; Carmi, Y.; Voronov, E.; Apte, R.N. Interleukin-1 $\alpha$. Semin. Immunol. 2013, 25, 430-438. [CrossRef] [PubMed]

10. Sabat, R. IL-10 family of cytokines. Cytokine Growth Factor Rev. 2010, 21, 315-324. [CrossRef]

11. Kwilasz, A.J.; Grace, P.M.; Serbedzija, P.; Maier, S.F.; Watkins, L.R. The therapeutic potential of interleukin-10 in neuroimmune diseases. Neuropharmacology 2015, 96, 55-69. [CrossRef]

12. Rayet, B.; Gélinas, C. Aberrant rel/nfkb genes and activity in human cancer. Oncogene 1999, 18, 6938-6947. [CrossRef]

13. Ling, J.; Kumar, R. Crosstalk between NFkB and glucocorticoid signaling: A potential target of breast cancer therapy. Cancer Lett. 2012, 322, 119-126. [CrossRef]

14. Jazwa, A.; Rojo, A.I.; Innamorato, N.G.; Hesse, M.; Fernández-Ruiz, J.; Cuadrado, A. Pharmacological targeting of the transcription factor Nrf2 at the basal ganglia provides disease modifying therapy for experimental parkinsonism. Antioxid. Redox Signal. 2011, 14, 2347-2360. [CrossRef] [PubMed]

15. Rojo, A.I.; McBean, G.; Cindric, M.; Egea, J.; López, M.G.; Rada, P.; Zarkovic, N.; Cuadrado, A. Redoxcontrol of microglial function: Molecular mechanisms and functional significance. Antioxid. Redox Signal. 2014, 21, 1766-1801. [CrossRef] [PubMed]

16. Pan, H.; Wang, H.; Wang, X.; Zhu, L.; Mao, L. The absence of Nrf2 enhances NF-kappaB-dependent inflammation following scratch injury in mouse primary cultured astrocytes. Mediat. Inflamm. 2012, 2012, 217580. [CrossRef] [PubMed]

17. Li, Y.; Lv, O.; Zhou, F.; Li, Q.; Wu, Z.; Zheng, Y. Linalool inhibits LPS-induced inflammation in BV2 microglia cells by activating Nrf2. Neurochem. Res. 2015, 40, 1520-1525. [CrossRef] [PubMed]

18. Perego, C.; Fumagalli, S.; DeSimoni, M.G. Temporal pattern of expression and colocalization of microglia/macrophage phenotype markers following brain ischemic injury in mice. J. Neuroinflamm. 2011, 8, 174. [CrossRef]

19. Shu, Z.M.; Shu, X.D.; Li, H.Q.; Sun, Y.; Shan, H.; Sun, X.Y.; Du, R.H.; Lu, M.; Xiao, M.; Ding, J.H.; et al. Ginkgolide B protects against ischemic stroke via modulating microglia polarization in mice. CNS Neurosci. Ther. 2016, 22, 729-739. [CrossRef]

20. Berndsen, R.H.; Weiss, A.; Abdul, U.K.; Wong, T.J.; Meraldi, P.; Griffioen, A.W.; Dyson, P.J.; Nowak-Sliwinska, P. Combination of ruthenium (II)-arene complex [Ru (n6-p-cymene) $\mathrm{Cl} 2$ (pta)](RAPTA-C) and the epidermal growth factor receptor inhibitor erlotinib results in efficient angiostatic and antitumor activity. Sci. Rep. 2017, 7, 43005-43020. [CrossRef]

21. Li, J.; Guo, L.; Tian, Z.; Tian, M.; Zhang, S.; Xu, K.; Qian, Y.; Liu, Z. Novel half-sandwich iridium(iii) imino-pyridyl complexes showing remarkable in vitro anticancer activity. Dalton Trans. 2017, 46, 15520-15534. [CrossRef]

22. Xu, Z.; Kong, D.; He, X.; Guo, L.; Ge, X.; Liu, X.; Zhang, H.; Li, J.; Yang, Y.; Liu, Z. Mitochondria-targeted half-sandwich ruthenium II diimine complexes: Anticancer and antimetastasis via ROS-mediated signalling. Inorg. Chem. Front. 2018, 5, $2100-2105$. [CrossRef]

23. Liu, Z.; Habtemariam, A.; Pizarro, A.M.; Fletcher, S.A.; Kisova, A.; Vrana, O.; Salassa, L.; Bruijnincx, P.C.A.; Clarkson, G.J.; Brabec, V.; et al. Organometallic half-sandwich iridium anticancer complexes. J. Med. Chem. 2011, 54, 3011-3026. [CrossRef] [PubMed] 
24. Lippert, B. Cisplatin: Chemistry and Biochemistry of a Leading Anticancer Drug; ZürichVerlag Helvetica Chimica Acta Wiley-VCH: Weinheim, Germany; New York, NY, USA, 1999.

25. Chohan, Z.H.; Iqbal, M.S.; Iqbal, H.S.; Scozzafava, A.; Supuran, C.T. Transition metal acetylsalicylates and their anti-inflammatory activity. J. Enzyme Inhib. Med. Chem. 2002, 17, 87-91. [CrossRef] [PubMed]

26. Kale, M.A.; Shelke, R.; Nawale, R.B. Zinc-aceclofenac complex: Synthesis, hydrolysis study and anti-inflammatory studies. Antiinflamm. Antiallergy Agents Med. Chem. 2014, 13, 36-44. [CrossRef]

27. Leung, C.H.; Lin, S.; Zhong, H.J.; Ma, D.L. Metal complexes as potential modulators of inflammatory and autoimmune responses. Chem. Sci. 2015, 6, 871-884. [CrossRef]

28. Levina, A.; Mitra, A.; Lay, P.A. Recent developments in ruthenium anticancer drugs. Metallomics 2009, 1, 458-470. [CrossRef]

29. Sava, G.; Bergamo, A.; Zorzet, S.B.; Gava, C.; Casarsa, M.; Cocchietto, A.; Furlani, V.; Scarcia, B.; Serli, B.; Iengo, E. Influence of chemical stability on the activity of the antimetastasis ruthenium compound NAMI-A. Eur. J. Cancer 2002, 38, 427-435. [CrossRef]

30. Li, W.; Han, B.J.; Yao, J.H.; Jiang, G.B.; Lin, G.J.; Xie, Y.Y.; Huang, H.L.; Liu, Y.J. Anticancer activity studies of a ruthenium (II) polypyridyl complex against human hepatocellular (BEL-7402) cells. Spectrochim. Acta Part A 2015, 150, 127-134. [CrossRef]

31. Peña, B.; David, A.; Pavani, C.; Baptista, M.S.; Pellois, J.P.; Turro, C.; Dunbar, K.M. Cytotoxicity studies of cyclometallated ruthenium (II) compounds: New applications for ruthenium dyes. Organometallics 2014, 33, 1100-1103. [CrossRef]

32. Khamrang, T.; Hung, K.C.; Hsia, C.H.; Hsieh, C.Y.; Velusamy, M.; Jayakumar, T.; Sheu, J.R. Antiplatelet activity of a newly synthesized novel ruthenium (II): A potential role for Akt/JNK signaling. Int. J. Mol. Sci. 2017, 18, 916. [CrossRef] [PubMed]

33. Hsia, C.H.; Velusamy, M.; Sheu, J.R.; Khamrang, T.; Jayakumar, T.; Lu, W.J.; Lin, K.H.; Chang, C.C. A novel ruthenium (II)-derived organometallic compound, TQ-6, potently inhibits platelet aggregation: Ex vivo and in vivo studies. Sci. Rep. 2017, 7, 9556. [CrossRef] [PubMed]

34. Ravishankar, D.; Salamah, M.; Attina, A.; Pothi, R.; Vallance, T.M.; Javed, M.; Williams, H.F.; Alzahrani, E.M.S.; Kabova, E.; Vaiyapuri, R.; et al. Ruthenium-conjugated chrysin analogues modulate platelet activity, thrombus formation and haemostasis with enhanced efficacy. Sci. Rep. 2017, 7, 1-16. [CrossRef] [PubMed]

35. Li, A.H.; Ahmed, E.; Chen, X.; Cox, M.; Crew, A.P.; Dong, H.O.; Jin, M.; Ma, L.; Panicker, B.; Siu, K.W.; et al. A highly effective one-pot synthesis of quinolines from o-nitroarylcarbaldehydes. Org. Biomol. Chem. 2007, 5, 61-64. [CrossRef]

36. Pan, C.W.; Zhou, G.Y.; Chen, W.L.; Zhuge, L.; Jin, L.X.; Zheng, Y.; Lin, W.; Pan, Z.Z. Protective effect of forsythiaside A on lipopolysaccharide/d-galactosamine-induced liver injury. Int. Immunopharmacol. 2015, 26, 80-85. [CrossRef]

37. Shi, Y.; Wang, Q.; Rong, J.; Ren, J.; Song, X.; Fan, X.; Shen, M.; Xia, Y.; Wang, N.; Liu, Z.; et al. Synthesis and biological evaluation of $(1,2,4)$ triazole[4,3-a] pyridine derivatives as potential therapeutic agents for concanavalin A-induced hepatitis. Eur. J. Med. Chem. 2019, 179, 182-195. [CrossRef] [PubMed]

38. Kong, Y.X.; Wu, G.; Chen, S.; Zhang, L.; Li, F.; Shao, T.; Ren, L.; Chen, S.Y.; Zhang, H.; McClain, C.J.; et al. Chalcone derivative L6H21 reduces EtOH+LPS-induced liver injury through inhibition of NLRP3 inflammasome activation. Alcohol. Clin. Exp. Res. 2019, 43, 1662-1671. [CrossRef]

39. Jayakumar, T.; Huang, H.C.; Hsia, C.W.; Fong, T.H.; Khamrang, T.; Velusamy, M.; Manubolu, M.; Sheu, J.R.; Hsia, C.H. Ruthenium derivatives attenuate LPS-induced inflammatory responses and liver injury via suppressing NF- $\mathrm{kB}$ signaling and free radical production. Bioorg. Chem. 2020, 96, 103639. [CrossRef]

40. Tirapelli, L.F.; Batalhão, M.E.; Jacob-Ferreira, A.L.; Tirapelli, D.P.; Carnio, E.C.; Tanus-Santos, J.E.; Queiroz, R.H.; Uyemura, S.A.; Padovan, C.M.; Tirapelli, C.R. Chronic ethanol consumption induces histopathological changes and increases nitric oxide generation in the rat liver. Tissue Cell 2011, 43, 384-391. [CrossRef]

41. Boje, K.M.; Arora, P.K. Microglia-produced nitric oxide and reactive nitrogen oxides mediate neuronal cell death. Brain Res. 1992, 587, 250-256. [CrossRef]

42. Hsia, C.H.; Jayakumar, T.; Sheu, J.R.; Hsia, C.W.; Huang, W.C.; Velusamy, M.; Lie, L.M. Synthetic Ruthenium Complex TQ-6 Potently Recovers Cerebral Ischemic Stroke: Attenuation of Microglia and Platelet Activation. J. Clin. Med. 2020, 9, 996. [CrossRef]

43. Komor, A.C.; Barton, J.K. The path for metal complexes to a DNA target. Chem. Commun. 2013, 49, 3617-3630. [CrossRef]

44. Wang, Z.; Ren, Z.; Hu, Z.; Hu, X.; Zhang, H.; Wu, H.; Zhang, M. Angiotensin-II induces phosphorylation of ERK1/2 and promotes aortic adventitial fibroblasts differentiating into myofibroblasts during aortic dissection formation. J. Mol. Histol. 2014, 45, 401-412. [CrossRef] [PubMed]

45. Wang, J.; Zhang, Y.; Yuan, Y.; Yue, T. Immunomodulatory of selenium nano-particles decorated by sulfated Ganoderma lucidum polysaccharides. Food Chem. Toxicol. 2014, 68, 183-189. [CrossRef]

46. Rai, A.; Kapoor, S.; Singh, S.; Chatterji, B.P.; Panda, D. Transcription factor NF-kB associates with microtubules and stimulates apoptosis in response to suppression of microtubule dynamics in MCF-7 cells. Biochem. Pharmacol. 2015, 93, 277-289. [CrossRef]

47. Medzhitov, R. Recognition of microorganisms and activation of the immune response. Nature 2007, 449, 819-826. [CrossRef]

48. Kwon, Y.W.; Cheon, S.Y.; Park, S.Y.; Song, J.; Lee, J.H. Tryptanthrin suppresses the activation of the LPS-treated BV2 microglial cell line via Nrf2/HO-1 antioxidant signaling. Front. Cell Neurosci. 2017, 11, 18. [CrossRef]

49. Lee, T.M.; Lin, S.Z.; Chang, N.C. Antiarrhythmic effect of lithium in rats after myocardial infarction by activation of Nrf2/HO-1 signaling. Free Radic. Biol. Med. 2014, 77, 71-81. [CrossRef] [PubMed]

50. Innamorato, N.G.; Rojo, A.I.; Garcia-Yague, A.J.; Yamamoto, M.; de Ceballos, M.L.; Cuadrado, A. The transcription factor Nrf2 is a therapeutic target against brain inflammation. J. Immunol. 2008, 181, 680-689. [CrossRef] 
51. Velagapudi, R.; Kumar, A.; Bhatia, H.S.; El-Bakoush, A.; Lepiarz, I.; Fiebich, B.L.; Olajide, O.A. Inhibition of neuroinflammation by thymoquinone requires activation of Nrf2/ARE signalling. Int. Immunopharmacol. 2017, 48, 17-29. [CrossRef]

52. Shah, Z.A.; Li, R.C.; Thimmulappa, R.K.; Kensler, T.W.; Yamamoto, M.; Biswal, S.; Doré, S. Role of reactive oxygen species in modulation of Nrf2 following ischemic reperfusion injury. Neuroscience 2007, 147, 53-59. [CrossRef]

53. Tannahill, G.M.; Curtis, A.M.; Adamik, J.; Palsson-McDermott, E.M.; McGettrick, A.F.; Goel, G.; Frezza, C.; Bernard, N.; Kelly, B.; Foley, N.H. Succinate is an inflammatory signal that induces IL-1beta through HIF-1alpha. Nature 2013, 496, 238-242. [CrossRef] [PubMed]

54. Oliver, C.N.; Starke-Reed, P.E.; Stadtman, E.R.; Liu, G.J.; Carney, J.M.; Floyd, R.A. Oxidative damage to brain proteins, loss of glutamine synthetase activity, and production of free radicals during ischemia/reperfusion induced injury to gerbil brain. Proc. Natl. Acad. Sci. USA 1990, 87, 5144-5147. [CrossRef] [PubMed]

55. Zapelini, P.H.; Rezin, G.T.; Cardoso, M.R.; Ritter, C.; Klamt, F.; Moreira, J.C.; Streck, E.L.; Dal-Pizzol, F. Antioxidant treatment reverses mitochondrial dysfunction in a sepsis animal model. Mitochondrion 2008, 3, 8211-8218. [CrossRef] [PubMed] 